\title{
IDENTIFICAÇÃO DE MOVIMENTOS DE MASSA NO MUNICÍPIO DE AGUDO/RS
}

\author{
Angéli. Behling ${ }^{(a)}$, Guilherme Cardoso da Silva ${ }^{(b)}$ \\ (a) Departamento de Geociências/Faculdade de Geografia, Universidade Federal de Santa Maria, \\ gelibehling@gmailcom \\ (b) Departamento de Geociências /Faculdade de Geografia, Universidade Federal de Santa Maria, gcsgeo@gmail.com
}

\section{EIXO: SISTEMA GEOMORFÓLOGICOS: ESTRUTURA, DINÂMICA E PROCESSO}

\begin{abstract}
Resumo
Os movimentos de massa podem ser classificados em quedas, escorregamentos, fluxos e rastejos, sendo um tipo de processo natural que pode vir a interferir na vida da população, seja ela rural ou urbana. O obejtivo do trabalho é localizar e identificar os movimentos de massa no munícipio de Agudo/RS, espacializando-os a partir da utilização de SIG. Para tanto, fez-se uma saída de campo em que foram identificados e pontuados todos os movimentos de massa encontrados, com a utilização de um recptor de GPS Garmin, modelo Legend H. Utilizou-se o software GPS TrackMaker para o download dos pontos, que foram representados em uma carta-imagem no software QGIS. Pode-se perceber a ocorrência de movimentos de massa, como: quedas, escorregamentos de diferentes tipos e rastejos. Concluiu-se que os movimentos de massa na área rural de Agudo merecem atenção, e apesar de não apresentarem grandes ameaças, se mostram capazes de causar transtornos à população.
\end{abstract}

Palavras chave: Movimento de massa; SIG; Agudo; Quarta Colônia

\section{Introdução}

Os processos de dinâmica superficial, como os movimentos de massa, estão ocorrendo com cada vez mais frequência em diversos lugares do mundo e do Brasil. Esses processos são popularmente conhecidos por escorregamentos, ou deslizamentos, envolvendo material que recobre a superfície das vertentes ou encostas, como solo, rocha e vegetação. São notáveis nas regiões montanhosas e serranas, principalmente onde predomina clima úmido, sendo mais frequêntes no Brasil nas regiões Sul, Sudeste e Nordeste (VANCÔR; ROLIM, 2012)

Em primeira instância o processo se caracteriza como fenômeno natural, onde pode ou não atingir áreas ou regiões habitadas pelo homem. Pelo fato de fazer parte da dinâmica do planeta, com manifestação própria, independentemente da presença do homem, os movimentos de massa são reconhecidos como os mais importantes processos geomorfológicos modeladores da superfície terrestre. Constituem-se no deslocamento de material (solo e rocha) vertente abaixo sob influência da gravidade, desencadeado pela interferência direta de outros agentes independentes (BIGARELLA, 2003). 
No momento em que ocorre contato direto com a população, o movimento se caracteriza como um desastre natural, e, assim, causa danos ou graves perturbações do funcionamento da comunidade, e/ou sociedade, podendo envolver perdas humanas, materiais ou ambientais de grande extensão (TOMINAGA et al, 2009).

No Brasil, os movimentos de massa estão entre os desastres de maior magnitude devido às características físicas locais. Sendo que os deslizamentos são relacionados à degradação ambiental de áreas frágeis e a ocupações irregulares (SANTOS, 2007).

Com relação ao Rio Grande do Sul, Reckziegel (2007) aponta que o estado tem sido frequentemente atingido pela ocorrência de desastres naturais associados a processos da dinâmica atmosférica e da dinâmica superficial, e cita que dentre eles se destacam os movimentos de massa.

O município de Agudo, localizado no centro do estado do Rio Grande do Sul, apresenta inúmeras ocorrências, podendo ser explicadas pela sua forma de relevo característica. As suas porções mais elevadas do município pertencem ao Planalto Serra Geral e as porções de encostas são pertencentes a Serra Geral, já as suas porções de menor elevação pertencem a Depressão Periférica do Jacuí, desta forma, tem-se uma justificativa para que estes movimentos ocorram de forma muito abrangente em seu território (RADAM BRASIL, 1986).

Desta forma, o objetivo deste trabalho é localizar e identificar os movimentos de massa no munícipio de Agudo/RS, espacializando-os a partir da utilização de SIG para melhor compreender a sua distribuição dentro dos limites do município.

\subsection{Caracterização da Área de Estudo}

O município de Agudo está localizado na região Centro Ocidental do Estado do Rio Grande do Sul e está inserido na Microrregião de Restinga Seca. Faz divisa com Ibarama ao norte, Lagoa Bonita ao noroeste, Cerro Branco ao leste, Paraíso do Sul e Restinga Seca ao sul e Dona Francisca ao oeste. Salienta-se que toda a sua porção oeste é banhada pelo Rio Jacuí, assim, se interligando com Restinga Seca a Sudoeste por uma ponte na RS 287, com Dona Francisca na RS348 e a noroeste limita-se com Nova Palma, com uma ponte localizada na Usina Hidrelétrica de Dona Francisca (Figura 1). IBGE (2010) e SCHIRMER (2010).

Quanto ao seu histórico, Agudo foi emancipado em 1959, desmembrando-se de Cachoeira do Sul e Sobradinho. A área total do município é de $536,12 \mathrm{~km}^{2}$, distanciando-se $250 \mathrm{~km}$ da capital Porto Alegre, apresentando uma população total de 16.722 hab. e densidade demográfica do território - Urbano/Rural de 31,19 hab./km² (IBGE, 2010). 


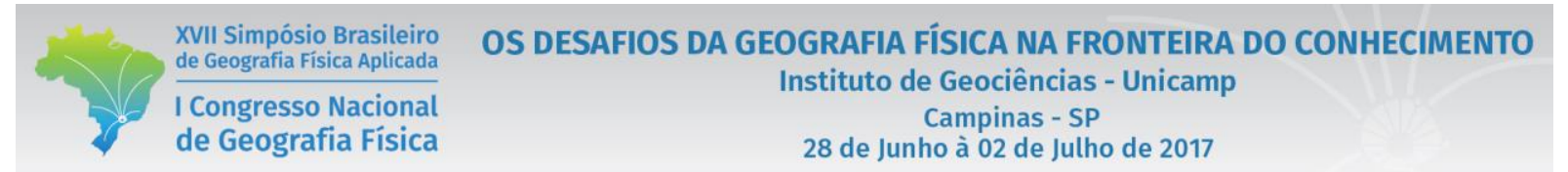

Mais da metade da população, 59\%, residem em zona rural e o restante, $41 \%$, em área urbana. Sua economia baseia-se no setor de serviços e no setor agropecuário (IBGE, 2010).

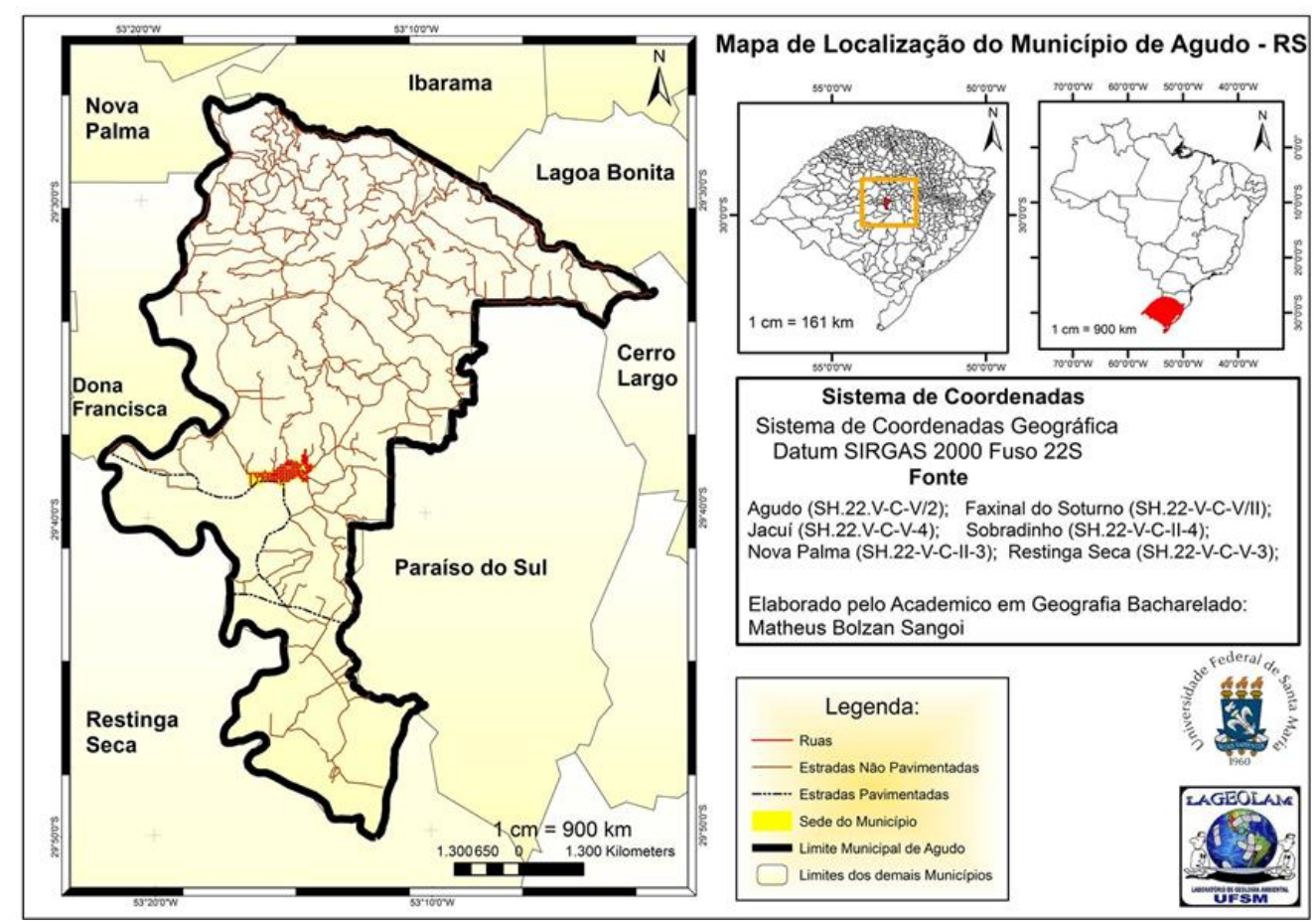

Figura 1- Localização do Munícipio de Agudo/RS. Org.: SANGOI, M. B. (2016).

As questões econômicas e ambientais se intercalam no município, visto que nas regiões de grande declividade, porção norte do município, há a produção animal (bovinos), e sua economia é fortementa caracterizada pelas atividades agrícolas, em específico a cultura do fumo. Nas regiões mais planas, porção sul, há produção ainda com alguns animais (bovinos), porém já se tem a inserção de maquinário, e os cultivos são principalmente arroz e fumo, tendo em vista que estas duas produções são as que se destacam na diferenciação do relevo local (SHIRMER,2010).

A porção norte do município, onde ocorrem os processos de movimentos de massa, se compõe por morros e morrotes com vertentes de declividade acentuada, sendo caracterizada como área de transição entre o Planalto e a Depressão Central gaúcha, conhecida como rebordo do Planalto (Müller Filho, 1970). O meio dessa região é favorável à fumicultura, com a presença de outras atividades associadas, pois são culturas que não necessitam de grandes áreas de lavouras, concentrando a agricultura familiar.

Em relação ao Sul e Sudoeste do município, tem-se a planície de inundação do Rio Jacuí com depósitos aluviais, local utilizado para o plantio do arroz, com menor ocorrência dos movimentos de massa. 


\section{Referencial Bibliogáfico}

Os movimentos de massa estão entre os processos de maior magnutide, sendo que se caracterizam em primeira ordem como natural, porém com a ação direta e mais frequente do homem o processo acaba por se tornar de risco. Desta forma, além da alteração do meio natural, outros parametros são de fundamental importância para o seu surgimento, como a geologia, geomorfologia, declividade, vegetação, entre outros. Assim, para melhor entendimento se necessita da análise de todos os fatores que são respeonsáveis pela dinâmica da superfície.

\subsection{Movimentos de Massa}

Os movimentos de massa fazem parte da dinâmica da paisagem, sendo um dos principais processos geomorfológicos responsáveis pela evolução do relevo e ocorrendo principalmente em áreas com relevo acidentado, como em regiões montanhosas.

Sendo assim, podem-se caracterizar os movimentos de massa, segundo Guerra e Marçal (2006 p. 75-76) como "o transporte coletivo de material rochoso e/ou de solo, onde a ação da gravidade tem papel preponderante, podendo ser potencializado, ou não, pela ação da água".

Segundo Small e Clark (1982) são os processos de movimentos de massa que apresentam impacto direto no uso da terra. A partir disto se destaca como um fenômeno natural extremo, também sendo responsáveis por inúmeras vítimas e adicionalmente aos danos financeiros diretos. Cabe salientar além disso a existência dos danos ambientais associados aos deslizamentos de terra, que, embora de difícil quantificação, são bastante importantes (associados a reservatórios, prejuízos à vegetação e distribuição de áreas agrícolas, entre outros) (BRESSANI \& BERTUOL, 2012).

Christofoletti (1980) salienta que os movimentos de massa são processos naturais, atuando na esculturação da paisagem, sendo eles: escorregamentos, rastejos, corridas, quedas de bloco, ou seja, remobilização do material oriundo do intemperismo que envolve uma série de condicionantes.

Assim, Casseti (1991) afirma que a partir do momento em que o homem atua sobre uma encosta, por meio de desmatamentos, cortes e aterros, ele altera sua estabilidade, aumentando a probabilidade de desencadear sua movimentação.

Maciel Filho e Nummer (2014) destacam que as principais causas para os movimentos de massa ocorrerem e modificarem o equilíbrio das forças atuantes nas vertentes, são: elevação do nível piezométrico em taludes, o efeito de oscilações térmicas, a diminuição dos parâmetros de resistência por intemperismo, as mudanças geométricas dos taludes, o efeito de vibração, o rebaixamento rápido do nível 
da água em barragens ou de enchentes, a erosão subterrânea retrogressiva (piping), a diminuição do efeito de coesão aparente, entre outros.

\subsection{Fatores Condicionantes}

Segundo Terzaghi (1967), as causas dos movimentos de massa podem ser subdivididas em duas grandes categorias por sua posição com relação aos taludes, são elas as causas internas, resultadas de uma diminuição da resistência disponível do material (aumento da pressão hidrostática, diminuição da coesão e ângulo de atrito interno por alteração), e as causas externas, provocadas por um aumento das tensões cisalhamento por modificação da morfologia dos taludes.

Para Augusto Filho e Virgili (1998), os principais condicionantes dos processos de instabilização de encostas são: climáticos (regime pluviométrico); tipo e distribuição dos materiais de substrato e encosta (taludes); geomorfologia; regime de águas de superfície e subsuperfície e características de uso e ocupação, incluindo a cobertura vegetal e as diferentes formas de intervenção antrópicas das encostas, cortes, aterros, concentração de água pluvial e servida.

Segundo o IPT - Instituto de Pesquisa Tecnológica (1991), o principal agente instabilizador de vertentes é a água, atuando de várias formas. Os processos erosivos, tanto interno quanto externos, têm como seu agente principal a água, pelo fato do carreamento ou arraste de partículas sólidas do solo, criando sulcos, ravinas ou vales, ou condutos escavados no interior de maciços rochosos (piping).

Existem ainda os fatores condicionantes dos fenômenos de instabilização de encosta, como os geológicos, que englobam litologia e estruturação dos maciços, os fatores climáticos, os fatores geomorfológicos, que englobam a tipologia das encostas e a declividade.

Pode-se afirmar que quanto maior a declividade, mais alta é a probabilidade de ocorrer o movimento, pelo fato de a instabilidade ser maior. Mas não se deve guiar a suscetibilidade a movimentos de massa unicamente por esse parâmetro (GUIDICINI \& IWASA, 1976). É importante destacar também a gravidade e os efeitos da presença ou ausência de vegetação.

A instabilização de vertentes é controlada por uma série de eventos, em caráter cíclico, desde sua origem geológica e geomorfológica. Os condicionantes do meio físico são fatores presentes na dinâmica superficial, que contribui para a ocorrência dos processos de movimentos de massa. Podem incluir a forma e a inclinação das encostas, pluviosidade, a presença ou não de vegetação, características do solo e rocha, natureza geológica (litológica e estrutural) do meio, tensão internas, abalos naturais e induzidos, e ainda a ação antrópica (BARROS, 2001). 
O Sistema de Informações Geográficas é caracterizado pela interação de programas, equipamentos, metodologias, dados e usuários, em sincronia, na intenção de emergir a possibilidade da coleta, armazenamento, processamento e a análise de dados georreferenciados, juntamente à produção de informação provinda de sua aplicação (TEIXEIRA, 1995).

O SIG - Sistema de Informações Geográficas é uma sigla originada do inglês GIS - Geographic Information System, situada dentro do contexto do geoprocessamento, e entrando como uma importante ferramenta na tentativa de quantificar e qualificar dados dentro da área de estudo, no objetivo de compreender melhor alguma especificidade da região.

São então sistemas capazes de capturar, gerenciar, manipular e analisar dados de fontes diversas, referenciados espacialmente visando a solução de problemas de planejamento e gerenciamento. Por meio desta ferramenta, é possível realizar análises complexas, com a integração de dados de diferentes fontes e escalas, criar banco de dados georeferenciados, sendo portadores de campos que indicam a localização das entidades neles armazenadas, além de produzir mapas por meio das técnicas da cartografia digital e realizar operações entre mapas através da álgebra de mapas (NCGIA, 1990; SOUZA, 2015). Ao permitir a organização das informações de uma área de estudo, os sistemas de informações geográficas não funcionam apenas como uma ferramenta que permite a manipulação dos dados, mas também, possibilita a análise, simulação e avaliação dos modelos pré-concebidos (SOUZA, 2015).

Neste sentido, Camargo et al., (2007) destaca que a inferência espacial é uma ferramenta importante no processo, que muito em voga na atualidade, permite a integração de dados espaciais de formatos distintos. Os estudos de SIG, com toda a certeza, são os mais mutáveis, visto que devido a sua relação com a informática, possuem alterações rápidas, que conferem uma característica bastante dinâmica. Além disso, o SIG envolve estudos de diversos ramos da Ciência da Computação, como Computação Gráfica, Banco de Dados, Inteligência Artificial e Engenharia de Software (LISBOA FILHO \& IOCHPE, 1996).

Pelo fato de os movimentos de massa ocorrerem de acordo com uma série de fatores, a utilização do SIG é de grande valia, principalmente pelo fato de poder ser empregado em diferentes estudos, como até mesmo relacionado a processos de prevenção (MARCELINO, 2007). Assim, Coppock (1995) salienta a relação do SIG com o Sensoriamento Remoto, e o Sistema de Posicionamento Global (GPS) na geração de dados para o estudo de fenômenos geográficos. Isso tudo com destaque para a vantagem do baixo custo, se comparado a outros processos que demandam uma verba bastante significativa (BONHAM-CARTER, 1996). 


\section{Materiais e Métodos}

Inicialmente buscou-se uma pesquisa a bibliografia para colaborar com a identificação dos movimentos de massa em campo.

Posterior a isso, realizou-se a saída de campo, no dia 14 de Outubro de 2016, em que foram identificados e pontuados todos os movimentos de massa encontrados, com a utilização de um recptor de GPS Garmin, modelo Legend $H$. Também foram tiradas fotografias para ajudar na identificação dos movimentos de massa.

Em laboratório foi feito o download dos pontos com o software GPS TrackMaker, em que os locais puderam ser especificados no computador. A partir de então, foi feita a exportação da malha de pontos no formato KML, para viabilizar a vizualização no software Google Earth Pro.

Com os pontos no formato KML e diante das fotografias tiradas, utilizou-se o software GeoSetter, para relacionar os dois arquivos, culminando em um arquivo com os movimentos georreferenciados juntamente com as fotografias, também no formato KML.

Foi elaborada uma tabela com a numeração, uma breve descrição e as coordenadas de doze pontos levantados. Posteriormente estes foram simplificados a seis pontos, identificando os movimentos de massa mais significativos. Por fim, houve a elaboração de uma carta-imagem no software QGIS, onde os pontos poderam ser melhor vizualizados e compreendidos para discussão na presente pesquisa.

\section{4. $\quad$ Resultados Finais}

Após as saídas de campo e as análises em laboratório, juntamente com os pontos do receptor de GPS, os movimentos de massa vistos em campo foram resumidos em seis, sendo eles, queda, escorremaneto planar, em cunha e circular e ratejos, conforme a Tabela 1.

Tabela I - Movimentos de massa presenciados a campo no município de Agudo - RS.

\begin{tabular}{ccc}
\hline Pontos & Descrição & Coordenadas \\
\hline $\mathbf{1}$ & Queda/esc. em cunha e planar & 281349.51 E 6734370.04 S \\
\hline $\mathbf{2}$ & Escorregamento planar & $280278.17 \mathrm{E} 6727803.02 \mathrm{~S}$ \\
\hline $\mathbf{3}$ & Escorregamento planar & $282397.97 \mathrm{E} 6726290.29 \mathrm{~S}$ \\
\hline $\mathbf{4}$ & Escorregamento planar & $278432.26 \mathrm{E} 6720843.61 \mathrm{~S}$ \\
\hline $\mathbf{5}$ & Rastejo/escorregamento circular & $279449.17 \mathrm{E} 6719362.54 \mathrm{~S}$ \\
\hline $\mathbf{6}$ & Rastejo/escorregamento circular & 278269.206724475 .59 \\
\hline
\end{tabular}




$\begin{aligned} & \text { XVII Simpósio Brasileiro } \\ & \text { de Geografia Fisica Aplicada }\end{aligned}$
$\begin{aligned} & \text { I Congresso Nacional } \\ & \text { de Geografia Física }\end{aligned}$

Relacionando com as fotografias tomadas em campo, pode-se verficar o Ponto 1, que correponde a três movimentos de massa bastante próximos, são eles: Quedas, escorregamento em cunha e escorregamento planar, conforme a Figura 2.

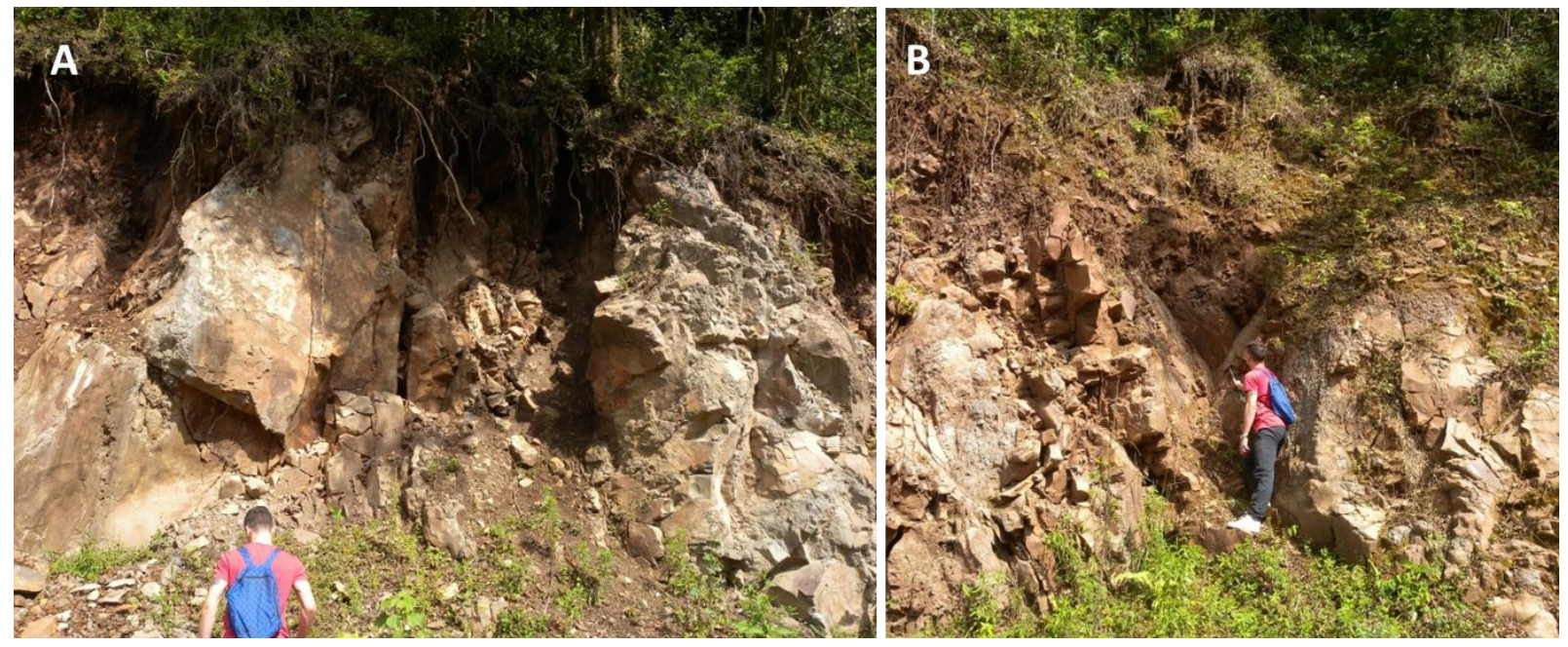

Figura 2 - A) Queda e escorregamento planar presenciados no campo no município de Agudo, no Ponto 1; B) Escorregamento em cunha presenciado no campo no município de Agudo, no Ponto 1.

Nos pontos 2, 3 e 4 foram presenciadas evidências de escorregamentos planares, conforme a Figuras 3.

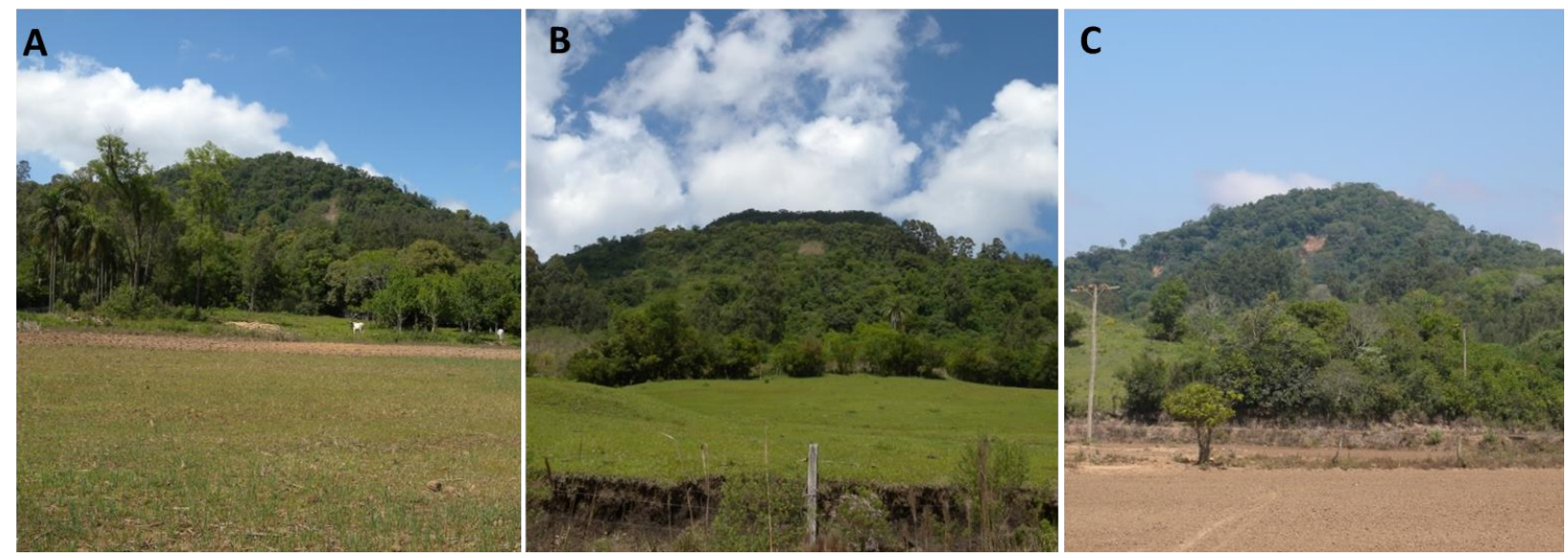

Figura 3 - A) Escorregamento planar presenciado no campo no município de Agudo, no Ponto 2; B) Escorregamento planar presenciado no campo no município de Agudo, no Ponto 3; C) Escorregamento planar presenciado no campo no município de Agudo, no Ponto 4.

Nos pontos 5 e 6 foram presenciados uma série de rastejos e escorregamentos circulares em sequência, que é um fenômeno comum dentro dos estudos de movimentos de massa. Essas situações podem ser observadas na Figuras 4. 


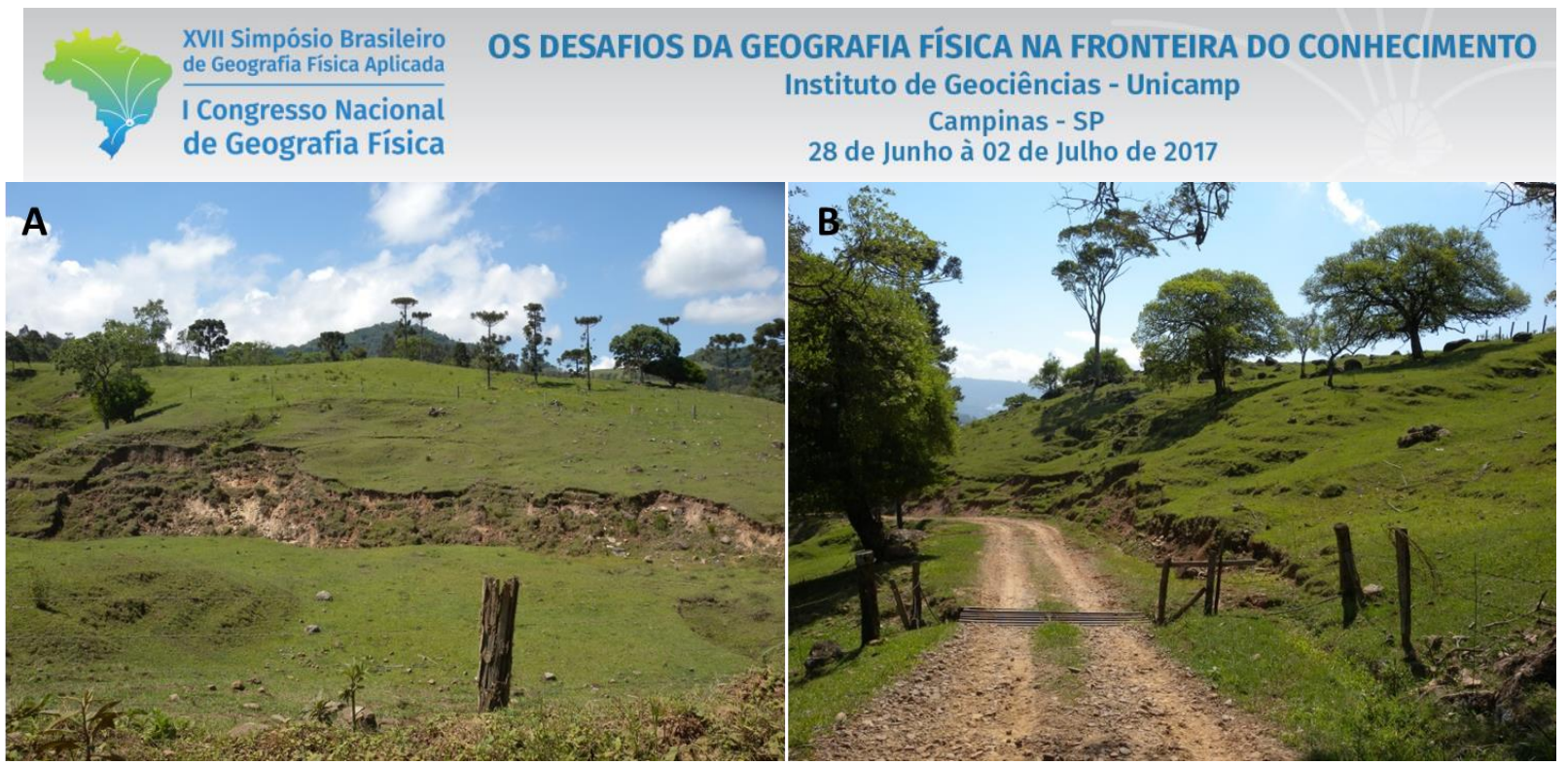

Figura 4 - A) Rastejos e escorregamentos circulares presenciados no campo no município de Agudo, no Ponto 5. B) Rastejos e escorregamentos circulares presenciados no campo no município de Agudo, no Ponto 6.

Para melhor comprender a localização dos movimentos de massa da presente pesquisa, foi elaborada uma carta-imagem visando colaborar com a pesquisas, de acordo com as coordenadas UTM já apresentadas na Tabela 1. O referido trabalho pode ser observado na Figura 5. 


\begin{tabular}{|c|c|}
\hline $\begin{array}{l}\text { XVII Simpósio Brasileiro } \\
\text { de Geografia Fisica Aplicada }\end{array}$ & $\begin{array}{l}\text { OS DESAFIOS DA GEOGRAFIA FÍSICA NA FRONTEIRA DO CONHECIMENTO } \\
\text { Instituto de Geociências - Unicamp }\end{array}$ \\
\hline $\begin{array}{l}\text { I Congresso Nacional } \\
\text { de Geografia Física }\end{array}$ & $\begin{array}{c}\text { Campinas - SP } \\
28 \text { de Junho à } 02 \text { de Julho de } 2017\end{array}$ \\
\hline
\end{tabular}

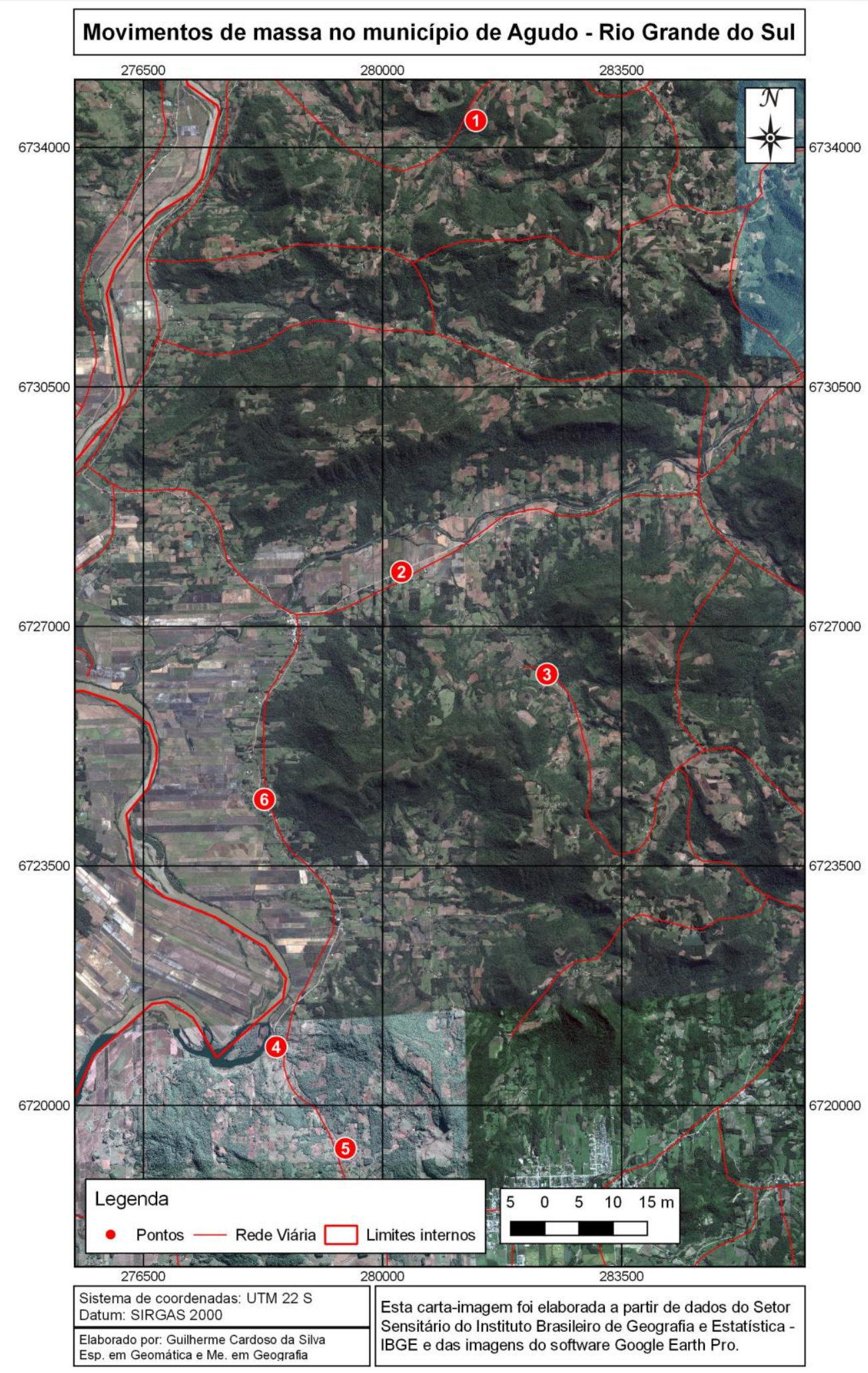

Figura 5 - Carta-imagem com a localização dos movimentos de massa evidenciados no campo da presente pesquisa, sendo 1- Queda/escorregamento em cunha e planar 2- Escorregamento planar 3- Escorregamento planar 3-

Escorregamento planar 4- Escorregamento planar 5- Rastejo e Escorregamento Circular 6- Escorregamento Circular. 


\section{Conclusão}

Sendo assim, percebe-se a relevância do estudo dos movimentos de massa, e pode-se constatar que existem eventos significativos no município de Agudo, na Quarta Colônia-RS, apesar dos poucas pesquisas existentes na área.

O estudo dos movimentos de massa é bastante expressivo no país, mas muitas vezes vê-se que algumas áreas são menospresadas pelo fato de não apresentarem eventos tão expressivos e/ou com grande potencial destrutivo.

É compreensível que áreas com movimentos de massa mais expressivos tenham maior apelo tanto da mídia quanto de estudos científicos, mas cabe salientar que outras áreas também merecem atenção, pois podem causar transtornos, como interrupção de estradas, perdas econômicas como a destruição de cultivos, e dentro do contexto do crescimento urbano, não é descartada a possibilidade de eventos futuros que atinjam de forma mais significativa a população da cidade de Agudo, principalmente com os movimentos de escorregamentos e quedas evidenciados no presente trabalho.

No Município ocorrem inúmeros processos de movimentos de massa principalmente na zona rural, mas o fato de não atingirem diretamente a população limita os registros realizdos pela Defesa Civil local. Entretanto, cabe salientar que muitos processos ocorrem em estradas, prejudicando também, desta maneira, o deslocamento da população e da produção agrícola.

\section{Bibliografia}

AUGUSTO FILHO, O.;VIGILI, J. C. Estabilidade de Taludes. In: OLIVEIRA, A. M. dos S.; BRITO, S. N. A. de (org).Geologia de Engenharia. São Paulo: ABGE-CNPq-FAPESP, 1998.

BARROS, E.J. Carta de risco de movimentos gravitacionais de massa, Zona Norte dos Morros de Santos, SP, com a utilização de Sistemas de Informações Geográficas. 2001. 149f. (Mestrado em Geociências e Meio Ambiente) Instituto de Geociências e Ciências Exatas, Universidade Estadual Paulista, Rio Claro.

BIGARELla, J.J. Estrutura e Origem das Paisagens Topicais e Subtropicais. Vol 3. Florianópolis. Ed; da UFSC, 2003.

BONHAM-CARTER, G. F. Geographic information systems for geoscientists: modeling with GIS. Ottawa: Pergamon, 1996.

BRESSANI, L. A.; BERTUOL, F. Alguns Escorregamentos do RS e SC e a Avaliação de Suscetibilidade e Risco de Encosta. In. (org): LACERDA, W. A.; PALMEIRA, E, M.; NETO, A, L. C.; EHRLICH, M.: Desastres Naturais: Suceptibilidade e Risco, Mitigação e Prevenção, Gestão e Ação Emergenciais. Rio de janeiro: COPPE/UFRJ, 2012.

CAMARGO, F.F.; ALMEIDA, C.M.; FLORENZANO, T.G.; CREPANI, E.; MEDEIROS, J.S. Avaliação dos Métodos Booleano, Fuzzy Gama e Bayesiano na Identificação de Áreas Suscetíveis a Movimentos de Massa no Município de São Sebastião/SP. In: SIMPÓSIO BRASILEIRO DE GEOGRAFIA FÍSICA APLICADA, 12, 2007, Natal. Anais... Natal: Universidade Federal do Rio Grande do Norte, 2007, v. 12.

CASSETI, V. Ambiente e apropriação do relevo. São Paulo: Contexto, 1991. 136 p. 
CHRISTOFOLETTI, A. Geomorfologia. São Paulo. Edgard Blucher Ltda, 2a . Ed. 188p., 1980.

COPPOCK, J. T. GIS and natural hazards: an overview from a GIS perspective. In: CARRARA, A.; GUZZETTI, F. Geographical information systems in assessing natural hazards. Dordrecht: Kluwer Academic Publishers, 1995.

GUERRA, A. J. T.; MARÇAL, M. S. Geomorfologia Ambiental, Rio de Janeiro: Bertrand Brasil, 2006.

GUIDICINI, G.; IWASA, O. Y. Ensaio de correlação entre pluviosidade e escorregamentos em meio tropical úmido. São Paulo: Instituto de Pesquisas Tecnológicas do Estado de São Paulo - IPT, 1976. 48 p. (Relatório n. 1080).

IBGE - Instituto Brasileiro de Geografia e Estatística. Censo. 2010. Disponível em< http://www.censo2010.ibge.gov.br/. >acessado em: 15 de Dezembro de 2016.

IPT - INSTITUTO DE PESQUISA TECNOÓGICAS. Manual de ocupação de encosta. São Paulo. 1991.

LISBOA FILHO, Jugurta; IOCHPE, Cirano. Introdução a sistemas de informações geográficas com ênfase em banco de dados. In: JAI - Jornada de Atualização em Informática, 15., 1996, Buenos Aires, Congresso da SBC. 16., Recife-PE, 1996. Anais... Buenos Aires, JAI, 1996, Recife, SBC, 1996.

MACIEL FILHO, C.; NUMMER, A. Introdução à Geologia de Engenharia. 5a ed. Santa Maria: Ed da UFSM, 2014.

MARCELINO, Emerson Vieira. Desastres Naturais: conceitos básicos. Santa Maria: INPE, 2007.

MÜLlER FILHO, I.L. Notas para o estudo da geomorfologia do Rio Grande do Sul, Brasil. Publicação Especial, Departamento de Geociências da UFSM, n. 1, 94 p., 1970.

NCGIA - National Center for Geographic Information and Analysis. NCGIA Core Curriculum. Edited by Michael F. Goodchild and Karen K. Kemp, Santa Barbara: University of California, 1990.

RECKZIEGEL, B. W. Levantamento dos Desastres Desencadeados por eventos naturais adversos no estado do Rio Grande do Sul de 1980 a 2005. Dissertação de Mestrado. UFSM. 2007.

SANTOS, Rozely F. dos. Vulnerabilidade Ambiental. Brasília: Ministério do Meio Ambiente, 2007. 192 p.

SHIRMER, G. J. Mapeamento Geoambiental Municipal de Agudo -RS. Trabalho de Graduação, Santa Maria, 2010.

SMALL, John.; CLARK, Michael. Encostas e intempéries. Cambridge University Press, Cambridge, Inglaterra, 1982.

SOUZA, Leonardo Andrade de. Cartografia Geoambiental e Cartografia Geotécnica progressiva em diferentes escalas: aplicação na bacia hidrográfica do Ribeirão do Carmo, municípios de Ouro Preto e Mariana, Minas Gerais. 2015. Tese (Doutorado em Geotecnia)- Universidade Federal de Ouro Preto, Minas Gerais, 2015.

TEIXEIRA A. Et. Al. Qual a melhor definição de SIG. Revista FATOR GIS, n.11, 1995.

TERZAGHI, K. Mechanism of Ladslides. PILCHER, E. (Tradutor). São Paulo: Departamento de Livros e Produções do Grêmio Politécnico, 1967. 41 p.

TOMINAGA, L. K. SANTORO, J.; AMARAL, R. do. Desastres naturais: conhecer para prevenir. São Paulo: Instituto Geológico, 2009. 50 p.

VANCÔR, R. N; ROLIM, S. B. A.: Mapeamento da Suscetibilidade a Deslizamento Usando Tecnicas de Estatistica Bivariada e Sistema de Informação Geográfica na Região Nordeste do Rio Grande do Sul. Revista Brasileira de Geomorfologia, V, 13, n. 1., 2012. 